\title{
Nymphê Calipso e seu duplo propósito na Odisseia de Homero
}

\author{
Mayã Fernandes ${ }^{1}$
}

Resumo: Este artigo se propõe a analisar como a ninfa Calipso busca realizar seu duplo propósito: efetivar o ritual de nymphagôgia e ocultar os viajantes que passam por sua ilha. Compreende-se que, sendo uma deusa-nymphê, Calipso não se distancia do estatuto social das mulheres e busca, através de artifícios de sedução, alcançar seus objetivos. Todavia, as questões aparecem quando seu estatuto ontológico não dialoga com a existência dos ideais do herói épico.

Palavras - chaves: ninfa; Calipso; imortalidade; sedução; Odisseia.

Résumé: Le présent article vise à analyser comme la nymphe Calypso recherche réaliser son double but: effectuer le rituel de la nymphagôgia et les voyageurs qui se cachent qui passent à leur île. Il est entendu que d'être une déesse-nymphe, Calypso est non loin du statut social des femmes et la recherche à travers des tours de séduction, à atteindre leurs objectifs. Cependant, apparaissent les problèmes lorsque son statut ontologique ne dialogue avec l'existence des idéaux du héros épique.

Mots-clés: nymphê; Calypso; immortalité; seduction; Odyssée.

\section{Introdução}

A Odisseia ${ }^{2}$ de Homero é marcada pelo retorno do herói Odisseu, que vive uma aventura em busca de seu lar. Nesse delongado percurso, Odisseu permanece durante sete anos com Calipso, nymphê de belas-tranças, de excepcional beleza e juventude (Od. 5.30), que se destaca das demais nymphai da epopeia pelo grau de envolvimento amoroso com o herói.

\footnotetext{
${ }^{1}$ Mestranda pelo Programa de Pós-Graduação em Metafísica, UnB. Bolsista CAPES. E-mail: ma.gfernandes@hotmail.com

${ }^{2}$ Nesse artigo será adotada a tradução e introdução da Odisseia de Christian Werner (2014).
} 
Em sua definição, Calipso reflete a necessidade intrínseca do que é ser uma nymphê e precisa realizar o ritual de nymphagôgia ${ }^{3}$. Todavia, ela recebe em sua essência a capacidade de ocultar. O termo Kalypsô significa "a que esconde" e, em conjunto com sua ilha, Ogígia, escondem do mundo aqueles que permanecem em seu território. Deste modo, como é possível cumprir esses dois propósitos ontológicos? É possível conciliá-los ou eles são excludentes? Para isso, investiga-se os artifícios de persuasão guardados com a nymphê e também sua suficiência para cumprir a sua finalidade: casar-se com o herói e ocultá-lo do restante do mundo grego.

A representação da deusa-ninfa Calipso na Odisseia ocorre nos cantos primeiro e quinto, onde sua imagem é vinculada a de uma deusa tanto maléfica, quanto essencial para a jornada do herói. Sabe-se que outras figuras femininas perpassam o caminho de Odisseu e que ganham características ambíguas na trama. Segundo Martin (2014, p. 57), são tantos e tão artísticos os retratos de mulheres fortes e fascinantes na Odisseia que mais de um crítico propôs que o poema tivesse sido composto para uma plateia predominantemente feminina. Adiante, o romancista Samuel Butler (1897) sugere que uma moça escreveu a epopeia. Ele observou com atenção que ninguém ri das mulheres ${ }^{4}$ na Odisseia, mesmo que as pessoas riam com frequência na obra.

Em Homero, é sabido que Calipso recebe Odisseu em sua ilha, Ogígia, já cansado da guerra e ferido no mar. Ele permanece com a ninfa longe da civilização e das atividades de um habitual herói grego5 ${ }^{5}$ Não é segredo que Odisseu consegue partir de Ogígia e que

\footnotetext{
${ }^{3} \mathrm{O}$ termo nymphagôgia é designado para o ritual de casamento. Na antiguidade Clássica, esse ritual modifica o estatuto feminino: de filha de seu pai à mulher, esposa de seu marido. Em outros termos, esse ritual caracteriza o acesso a um estatuto social novo, definido por uma troca de bens e pela coabitação com um novo responsável (kurios), o esposo, cidadão ateniense. Além disso, no plano alimentar ocorre uma significativa mudança. A esposa passa a alimentar-se de cereais, principalmente de cevada, para representar a sua inserção na agricultura. Para os Gregos, o cultivo de grãos simboliza a realização da civilização e em relação às mulheres, quando efetivam o ritual de passagem de jovem à esposa, passam por outra passagem de natureza à cultura. Para saber sobre o casamento como rito de passagem, cf. MAGNIEN, 1936, p.115136.

${ }^{4} \mathrm{Na}$ Odisseia, a quantidade de figuras femininas que realizam papéis fundamentais para o enredo da obra é expressivo. Segundo Knox (2011, p.73) dentro da obra, é possível listar as seguintes personagens: Calipso, Circe, a ninfa Ino, Areta e Nausica, Cila, Caríbdis e a mulher gigantesca, Idoteia, Helena, Penélope, Euricleia, Atena, a siciliana que cuida do velho Laertes, a ama-seca fenícia que sequestra o jovem príncipe Eumeu, Eurínome, Melântia, Iftima e as que estavam entre os mortos: Tiro, Antíope, Alcmena, Jocasta, Clóris, Leda, Ifmedeia, Fedra, Prócris, Eurífile.

${ }^{5}$ Além das atividades laborais dentro da pólis, o homem grego para construir sua fama necessita de grandes feitos. Nesse sentido, a fama viria com as conquistas nas batalhas e nos prêmios pelas navegações. Um exemplo disso aparece nos cantos iniciais da Odisseia, em que Telêmaco sai em busca de notícias de seu pai e para fazer a sua própria glória.
} 
sua fuga pode ser lida de diversas maneiras ${ }^{6}$. Todavia, esse artigo não busca analisar o porquê do herói retorna para sua pátria, mas busca entender por qual motivo a nymphê oculta-o por tanto tempo.

Calipso é apresentada como a amante insaciável, deusa perfeita que aprisiona os viajantes que resolvem desembarcar em sua ilha por uma ironia do destino. Rodeada de aspectos amorosos, não se pode negar que a história de Calipso mostrou-se sedutora aos olhos dos leitores posteriores a Homero, e a imagem projetada sobre a ninfa afigura malícia, dissimulação e perigo. Nessas leituras, pouco se relata sobre a sua essência e o seu propósito. Não se explica acerca de sua origem e o porquê de suas ações em relação aos homens. Entender essa personagem considerando sua definição e seu papel dentro da Odisseia pode desmistificar o imaginário criado em torno de Calipso. Para tanto, cabe salientar que essa pesquisa se distancia de leituras de gênero que partem do marco hegeliano público/privado, e, assim sendo, pouco conversa com as teorias feministas contemporâneas. Tal decisão é importante para ressaltar que a interpretação apresentada é construída com base nas evidências dentro da própria Odisseia, e em estudos que evitam a utilização de conceitos que se distanciam da antiguidade.

Assim, para avançar a investigação, o presente artigo divide-se nas seguintes seções: 1. As nymphai e o ritual da nymphagôgia; 2. Calipso, a ninfa que oculta; 3. Calipso e seus artifícios de sedução em prática. A partir destas análises é possível compreender Calipso e seu inevitável fim (Od. 5.144), já que permanecer sozinha em sua ilha não parece ser uma opção.

\section{As nymphai e o ritual da nymphagôgia}

No imaginário, as ninfas são belas jovens que vivem nos campos, bosques, fontes e lagos, habitando grutas. Segundo Ribeiro (2010), o termo ninfa é adotado para divindades da natureza, de onde personificam sua fecundidade e a graça. É perceptível que essas personagens possuem como ocupação as atividades de fiar e cantar e por vezes acompanhavam o séquito de divindades femininas importantes, como Ártemis (Od. 7.

\footnotetext{
${ }^{6}$ Pode-se citar como exemplo as leituras realizadas da passagem no Tratado Sobre o Belo de Plotino (séc. III E.C.), filósofo bem posterior a Homero. Em algumas dessas leituras, a fuga de Odisseu pode simbolizar a figura da alma individual que abandona as belezas sensíveis ou a alma do amante que deseja amar a beleza inteligível. Para uma análise mais detalhada sobre como Calipso e Odisseu são lidos pela filosofia, cf. BUFFIERE, 1956.
} 
100-110), os Sátiros e Centauros (DALMON, 2011).

Segundo Gantz (2004), as nymphai aparecem em boa parte da literatura antiga7, permeando o universo feminino. Dentro da Odisseia, algumas personagens aparecem relacionadas ao termo. Para algumas comentadoras como Pache (2013, p.1), as nymphai são divindades imortais, sobretudo caracterizadas por serem jovens belas e por representarem a figura da noiva. Podem ser perigosas quando demonstram desejo por um mortal. Esse mortal, quando experimenta a epifania de uma nymphê, é dito "apreendido pelas ninfas". De acordo com essa definição, algumas deusas na Odisseia são chamadas de nymphê, principalmente em relação às deusas que se encontram em estado transitório, convivendo com deuses e humanos, como é o caso de Calipso (Od. 1.14) e da ninfa Circe (Od. 10.136). O termo nymphê, todavia, também é utilizado para mulheres mortais que evidentemente estavam gozando da juventude e beleza, como Helena e Penélope ${ }^{8}$. Além disso, na Odisseia, não existe uma distinção exata ao chamar as ninfas de deusas, já que essas compartilham da imortalidade ao mesmo tempo em que vivem no mundo mortal ${ }^{9}$.

Compreende-se que as nymphai possuem influência direta de Afrodite, pois essa deusa guarda a passagem da infância para o ápice do amor erótico, justificando assim as características de sedução que essas jovens possuem (LOURAUX, 1990, p. 53). Aparentemente, ao buscar características presentes nos dois tipos de ninfas, mortais e imortais, encontram-se aspectos como a juventude, beleza exacerbada e serem regidas por Afrodite. Nesse sentido, ao tratá-las isoladamente, observa-se que as ninfas mortais aparecem dentro do estatuto das mulheres, enquanto as nymphai imortais participam do mundo dos deuses e dos humanos. Nessa divisão, o estatuto das mulheres é atribuído a Pitágoras, já que o filósofo teria inventado essas palavras, além de ter tirado de denominações divinas a designação de categorias etárias femininas:

\footnotetext{
${ }^{7}$ Entre as ocorrências, as ninfas aparecem na Ilíada, Odisseia, Teogonia, Hinos homéricos... Para acompanhar todas as passagens, cf. GANTZ, 2004.

${ }^{8}$ Curiosamente, Penélope, mesmo já tendo efetivado o ritual da nymphagôgia, é obrigada a realizá-lo novamente, caso Odisseu não retorne para Ítaca. Deste modo, Penélope é nomeada como uma nymphê, permanecendo em um estado de transição, já que não se encaixa no estatuto de gynê. Consequentemente, com o exemplo de Penélope, pode-se questionar: em qual estatuto a mulher com filhos, porém sem marido, se adequa?

${ }^{9}$ Circe é outra deusa-ninfa que aparece na Odisseia. Ela permanece com Odisseu durante o período de um ano e tem papel decisivo na história do herói. Com sua ajuda, Odisseu consegue passar pelo Hades e seguir viagem. Para ver mais sobre essa personagem, Cf. Od. (10. 136-555).
} 
Assim, Perséfone remete por seu nome (koré) à jovem solteira, a ninfa (nymphê) à mulher que acaba de se casar com seu esposo, e Deméter (mêtêr) à esposa que já gerou filhos (CALAME, 2013, p. 123).

Calame (203, p. 123) afirma que, ao recolher a glosa, o relator não se enganou no léxico, a não ser quando definiu as nymphai como as jovens recém-casadas. Por outro lado, existia uma relação dessas jovens com o clitóris, para simbolizar o gozo físico, além de a jovem noiva estar sobre influência direta de Eros e Afrodite.

O estatuto da nymphê foi reconhecido oficialmente por M. Detienne (1974), que adota a reformulação feita por Jâmblico (IV E.C) ao definir precisamente a distinção entre koré, substituída por parthernos ${ }^{10}$ (a adolescente); a nymphê (jovem casada até o momento de seu parto); e mêtêr, substituída por gynê ${ }^{\mathrm{l}}$ (a mulher adulta).

Na Grécia Arcaica e Clássica, os rituais faziam parte do cotidiano da sociedade. De extrema importância para as relações sociais, eles modificavam e regiam a organização da pólis e principalmente do oíkos. No caso da figura da nymphê, sendo ela a protagonista ${ }^{12}$ do ritual de nymphagôgia, passa por uma iniciação desde a juventude, com uma educação ${ }^{13}$ voltada à realização do rito. Mas qual a importância do ritual de casamento para os gregos?

Segundo a tradição iconográfica, as representações do casamento de Thétis e Peleu foram utilizadas por toda a antiguidade grega como paradigma de como deve ocorrer um cortejo nupcial. Não adentraremos questões específicas acerca do ritual em si, mas algumas características nesse casamento em específico são importantes para ler a passagem de Calipso, como, por exemplo, a união entre uma imortal e um mortal.

\footnotetext{
${ }^{10}$ Calame relata que o termo parthenos na antiguidade clássica não era vinculado ao conceito de virgindade mariano. Para Calame, o estatuto da mulher nada correspondia à questão biológica sexual e a virgindade não possuía teor valorativo (2013, p.162).

${ }^{11}$ Outra característica entre o estatuto da nymphê e da gynê é que a mulher só será considerada uma mulher adulta caso tenha filhos. Curiosamente, Penélope, mesmo já tendo efetivado o ritual da nymphagôgia, é obrigada a realizá-lo novamente, caso Odisseu não retorne. Permanecendo em um estado de transição o qual não se encaixa no estatuto. Para saber mais, cf. CALAME, 2013.

${ }^{12}$ Sabe-se que além da figura da noiva, as figuras das deusas Afrodite, Hera e Artémis são relacionadas tanto no percurso de todo o ritual, até a sua consagração e transição da nymphê para gynê. Para ver mais, cf. DETIENNE, 1981.

${ }^{13}$ Pouco se encontra sobre a educação feita através de um sistema, para jovens, com caráter iniciático aos rituais da nymphagogia.
} 


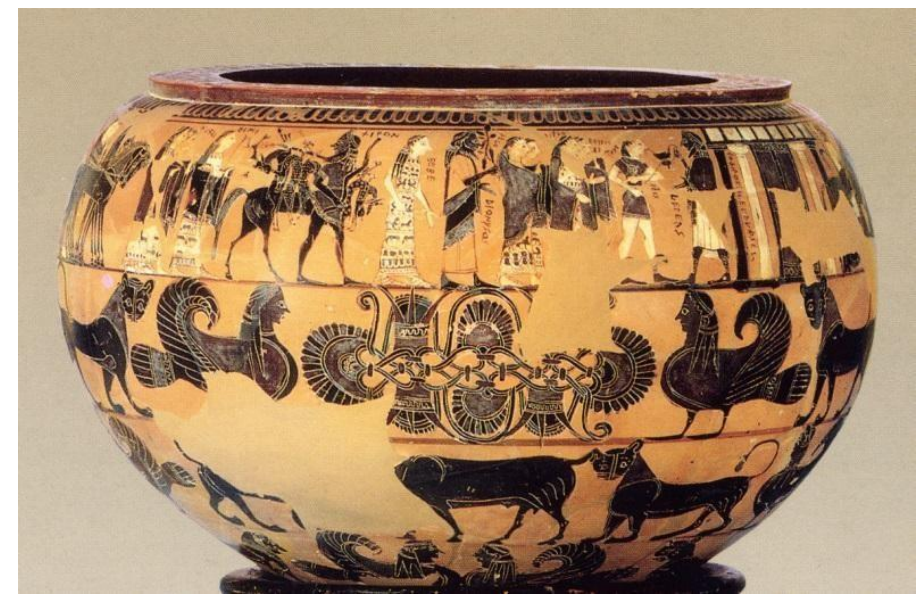

Fig. 1 Casamento de Thétis e Peleu. Dinos; vers 580. Londres, British

\section{Museum.}

Ao observar a imagem (Fig.1), percebe-se que no cortejo nupcial está presente a noiva em marcha pelo lado esquerdo superior. Do lado direito superior, o noivo aguardando em seu oikos a chegada da noiva. Além desses personagens, nota-se a presença de outras divindades. Segundo Lissarrague (1990, p. 208), trata-se de um casamento incomum entre a filha do imortal Nereu, Thétis, com Peleu, um mortal. Desse modo, acompanham a marcha do lado esquerdo personagens como Quíron, o centauro de Aquiles, Héstia e Deméter. Do lado direito é possível ver pares: Zeus/Hera, Poseidon/Anfitrite, Apolo/Ártemis, Afrodite/Ares. Conforme pode ser verificado na parte inferior do vaso, também fazem parte do ritual as Horas, Musas e as Moiras.

O casamento nas representações iconográficas ${ }^{14}$ perpassa o mundo mortal e imortal, carregando em si a importância para o equilíbrio social. Indica-se que dentro do casamento, a mulher filha de cidadãos passa a conviver com o restante da cidade. Além disso, explica-se que a noite de núpcias simboliza um elo de confiança e de philotês recíproco. Assim, de Homero a Xenofonte, a realização do desejo amoroso, a união ${ }^{15}$ matrimonial na Grécia funda a sexualidade como princípio de fidelidade. Nessa relação,

\footnotetext{
${ }^{14}$ Para acompanhar outras referências acerca do ritual do casamento e dos ritos fúnebres, cf. LISSARRAGUE, 1990.

${ }^{15}$ Percebe-se que a diferença entre a philia encontrada em casais homófilos masculinos e homófilos femininos assemelha-se ao conjugado no casamento. Todavia, a grande diferença parece estar nas implicações judiciais sociais que o casamento possui. Afinal, essa união através do ritual da nymphagogia é legitimada. Suas implicações perpassam as divisões de bens e elo entre famílias, até ao restante dos filhos legítimos.
} 
pode-se pontuar que as diferenças existentes de gênero parecem se apagar, pois a confiança recíproca é instituída por Eros (CALAME, 2013, p.115).

Para além das representações iconográficas, o universo do casamento e do oíkos é mais maleável, sobretudo no século V A.E.C. A união fundada no cotidiano, ou seja, fora dos ritos legitimados pela pólis, mostra receptividade a outras mulheres que não fazem parte desse estatuto. Esse é o caso das heteras ${ }^{16}$, concubinas que viviam em um estado intermediário na sociedade.

Quando se explica que as nymphai mortais em seu estatuto gozam de uma posição transitória, as nymphai imortais parecem sofrer resistência quanto à modificação de seu estado. Deste modo, por vezes, sua posição pode ser confundida com a das heteras, encontrando-se em um estado intermediário entre deuses e humanos, oscilando entre os dois mundos. Tratando-se de Calipso, qual a sua real aproximação com o estatuto da jovem noiva? É possível para ela modificar sua situação de nymphê e consagrar o ritual da nymphagôgia?

\section{Calipso, a ninfa que oculta.}

A origem de Calipso é narrada na Teogonia de Hesíodo e sua existência é entrelaçada à imortalidade dos Titãs. Filha de Tétis ${ }^{17}$ e Oceano, em conjunto com suas irmãs faz parte da prole conhecida como Oceânidas (RIBEIRO JR, 2010, p. 553). Assim, Calipso participa da linhagem de "Jovens, que pela terra, a meninos tornam varões" (Th. $345)^{18}$. Admite-se que desde sua origem, a posição de nymphê está delimitada e seu propósito descrito. Porém, ao assumir os desígnios de seu nascimento e enquanto nymphê, que busca o ritual da nymphagôgia, Calipso - a que esconde - encontra em seu nome uma

\footnotetext{
${ }^{16}$ Hetairas são jovens que assumem traços próprios ao estatuto intermediário da nymphê, contemplando especialmente as jovens alunas de Safo, orientando-se sexual e socialmente para conviver com os homens. Elas podem ser consideradas philê (amiga) ou como pornê (prostituta). Além disso, seu estatuto é intermediário no sentido em que ele pode oscilar entre outros estatutos, e porventura garantir a convivência dessa jovem dentro no oikos como uma nymphê ou gynê.

${ }^{17}$ Embora no português alguns nomes em grego tenham a mesma grafia é importante não confundir a titânica Tétis $(\theta \eta \tau \dot{\varsigma} \varsigma)$ com a nereida Tétis $(\theta \varepsilon ́ \tau \iota \varsigma)$. A primeira é mãe de Calipso, enquanto a segunda é filha de Nereu e casou-se com o rei Peleu, conforme se explica nas páginas anteriores.

${ }^{18}$ As passagens referenciadas da Teogonia de Hesiodo são de tradução de Christian Werner (2013).
} 
característica ambígua que, em determinado momento, mostra-se um problema para a efetivação do casamento ao considerar o ideal de herói grego.

Desse modo, com a finalidade de tentar cumprir seu propósito enquanto ninfa e enquanto deusa que esconde, Calipso possui três artifícios de persuasão: 1. a ambiguidade do ocultamento; 2. Seu estado natural de deusa-nymphê; 3. A oferta da imortalidade e juventude eterna.

Primeiramente, analisa-se o significado do nome de Calipso. A deusa-ninfa em conjunto com sua gruta Ogígia simboliza o oculto. Ainda na origem de seu nome, o primeiro sentido do termo Kalypsô (a partir do verbo Kalýptein) é o mesmo de "a que esconde" (VERNANT, 1989, p.147). Como é sabido, esse significado demonstra uma das características essenciais da jovem, que resulta na aversão dos deuses e homens, como pode ser compreendido na fala de Hermes: "Zeus me ordenou que cá viesse, sem eu querer; quem de bom grado, cruzaria tanta água salgada, incontável?” (Od. 5.99-101). Segundo Louden (1999, p. 106), retomando o sentido transparente do nome Kalypsô em grego, Calipso segue cumprindo o prometido por seu nome, pois não apenas esconde o herói, mas ameaça também esconder a intriga da Odisseia. Ainda com o caráter de ocultamento, Ogígia, a ilha de Calipso, aparece semelhante ao mundo subterrâneo, em que tudo permanece estagnado e morto (GÜNTER apud ASSUNÇÃO, 2011). Essa capacidade de ocultamento pode ser classificada como uma das características de sedução da ninfa, já que o viajante que chega à ilha dificilmente conseguirá seguir o seu caminho sem o auxílio dos deuses.

Assim, a ninfa e sua ilha têm em essência fatores que seduzem e afastam. Seu lugar na sociedade é intermediário. Longe dos humanos e longe dos deuses (Od. 5.99101), Calipso encobre a si e aos outros que se aproximam. Desse modo, a ninfa representa grande ameaça para os ideais do humano grego: a perda da identidade. Entretanto, o efeito do ocultamento é ambíguo, uma vez que, por um lado, permanecer para sempre com Calipso parece impossível, simboliza a morte para o herói grego. Por outro lado, ao permanecer com ela e conseguir partir, torna-se uma grande tarefa para o herói, uma história para ser contada entre os humanos pela manutenção do kléos ${ }^{19}$.

\footnotetext{
${ }^{19}$ Werner (2001) comenta acerca das ambiguidades existentes no Kléos de Odisseu, e como o seu ocultamento e os empasses na viagem de retorno à Ítaca interferem na manutenção de uma fama já conquistada pelo herói na guerra de Tróia.
} 
A escolha de permanecer longe da ninfa ganha força ao entender a segunda característica de sedução. Na Odisseia, depois de sete anos, é possível observar a postura arredia do herói perante a espera na ilha da nymphê, uma vez que ele não está feliz e anseia pelo retorno. Todavia, é questionável por que Odisseu permaneceu tanto tempo na ilha da ninfa. Afinal, quais belezas seriam essas capazes de seduzir até mesmo o astuto Odisseu? A descrição da ilha de Ogígia guarda em si surpresas tão belas quanto a figura da ninfa. Nesse espaço existe:

Bosque havia em torno da caverna, verdejante:

Amieiro, choupo-preto e perfumado cipreste.

Lá repousavam aves-comprida,

Marinhos, que se ocupam de feitos marítimos.

(Od. 5.63-67)

Em Ogígia, há água em abundância e vida animal, todas as condições necessárias para que Odisseu sobrevivesse ao lado da ninfa. A beleza da ilha de Ogígia causa arrebatamento até em deuses: "mesmo um imortal lá chegando, se admiraria ao olhar e se deleitaria no juízo" (Od. 5.73-74). Com exuberância e opulência, nem o imortal deixou de contemplar a beleza do canto de Calipso (Od, 5.6o-61).

Calipso possui a sua própria beleza como poder de sedução. Nela é possível encontrar a beleza na música, já que é normal ninfas realizarem atividades de cantar e tecer perfeitamente. Recorda-se que toda nymphê é regida por Afrodite e seus encantamentos ganham força quando visam alcançar o amor. O canto da ninfa aproxima até imortais como Hermes, causando fascínio em um deus, inebria o amante que, apaixonado, acredita estar em face de seu verdadeiro amor.

A terceira ferramenta de sedução de Calipso é a sua capacidade de conceder a imortalidade e juventude eterna. A oferta da deusa mostra-se uma versão sofisticada, já ofertada por Aurora de róseos dedos ${ }^{20}$, como um dos últimos artifícios da nymphê para efetuar o casamento. Segundo Vernant (1989, p.15o) essa tentativa de sedução de Calipso garante ao humano que permanecer com ela a capacidade de acompanhar a vida imortal da deusa. Ora, pouco faz sentido conviver com um amante mortal que envelhece com o tempo, a morte seria uma certeza. Porém, para um herói épico, permanecer imortal e

\footnotetext{
${ }^{20}$ Cf. nota 22.
} 
jovem, mas esquecido com Calipso longe do cotidiano grego é similar à morte. Em vista disso, pode-se sinalizar que não existem problemas nessa característica de sedução da deusa, pois a questão está no receptor da oferta. Caso ele seja um herói em busca de reconhecimento entre os gregos, dificilmente concorde com essa versão de imortalidade.

\section{Calipso e seus artifícios de sedução em prática.}

Desde o início da Odisseia, as deusas-nymphai estão presentes, como se pode observar no canto primeiro, em que Atena, ao relatar a Zeus a situação atual de Odisseu, diz que este permanece na ilha de Ogígia, por sete anos, obrigado a conviver com a nymphê Calipso (Od, 1. 15-20). Atena continua narrando a Zeus:

Pois ninguém se lembra do divino Odisseu, aquele que regeu, e era como um pai amigável.

Mas ele está em uma ilha sofrendo forte agonia, no palácio da ninfa Calipso, que o retém e ele não consegue atingir sua terra pátria.

(Od. 5. 11-15)

Na narrativa de Atena é possível ver indícios sobre dois pontos importantes para compreender Calipso. 1. De algum modo, Odisseu, o herói da guerra de Troia, permanece esquecido da civilização mesmo com todos seus feitos; 2. Calipso é um dos fatores que fortalece o esquecimento, pois não permite o seu retorno para Ítaca.

Atendendo ao pedido de Atena, Hermes a contragosto viaja para a ilha de Calipso, com o aviso de que ela deveria deixar Odisseu partir (Od. 5.110-115). A notícia parece abalar a ninfa, que contrapõe explicando a imposição dos deuses em não permitir que deusas se relacionem com mortais ${ }^{21}$, e parece reivindicar a permanência com o herói, pois:

\footnotetext{
${ }^{21}$ A relação entre deuses e mulheres parece ser corriqueira dentro do universo imortal. Entretanto, quando o vínculo se estende entre deusas e homens, a relação é penalizada. Assim, podem ser citados os exemplos elencados por Calipso na Odisseia. Ela conta que Aurora de róseos dedos apaixonou-se por um mortal e pediu para que Zeus concedesse a imortalidade ao amado. Zeus concedeu a imortalidade e não a juventude, o que acarretou em um destino funesto para o amado, que envelhecia eternamente, então acabou virando uma crosta esquecida em um canto do palácio. Outro exemplo do castigo dos deuses é de Deméter de belas tranças, que amou Iásion e se uniu em leito. Mas Zeus apercebeu-se depressa e logo atingiu e matou o amante com um relâmpago cadente $($ Od. $\mathrm{V}, 120-125)$.
} 
A ele salvei enquanto a quilha cavalgava, sozinho, pois sua nau veloz, com um raivo cintilante Zeus atingiu e despedaçou no meio do mar vinoso. (Od. 5. 130-136)

Mesmo sabendo das impossibilidades de uma deusa e um humano permanecerem juntos (Od. 5. 120-129), Calipso argumenta contra Hermes que ela deve permanecer com Odisseu. Ela parece ignorar o fracasso dessas uniões, sofisticando suas formas de sedução. Indica-se que supostamente a insistência da ninfa ocorre pelo fato de que, embora essas uniões não possam ser legitimadas para todos, deuses e humanos (Od. 5. 120), elas acontecem.

Ao analisar o mito de Calipso, compreende-se que é possível encontrar duas narrativas. A conhecida pela Odisseia e a breve descrição da Teogonia. Hesíodo descreve as deusas que se uniram com mortais e revela que desses relacionamentos as ninfas tiveram filhos (Th.965) ${ }^{22}$. Nesse relato, Odisseu e Calipso não apenas tiveram uma relação, como dela nasceu Nauveloz e Naútico (Th. 1017).

Na Odisseia não aparece a descrição do nascimento dos filhos dos dois em Ogígia e nem sinais de que isso possa ter ocorrido. Todavia, não se pode negar que existia um jogo amoroso entre Calipso e Odisseu. Comentadores como Assunção (2011, p. 165) indicam que existem indícios dessa união consensual dentro da passagem em que Odisseu permanece com Calipso, em que existia reciprocidade. Segundo o autor, a passagem que garante essa afirmação é a em que Calipso:

Achou-o na praia, sentado; nunca em seus olhos as lágrimas secavam, e ia-se sua doce vitalidade, chorando pelo retorno, pois já não lhe agradava a ninfa.

(Od. 5, 151-153)

Ao considerar a frase em que "pois já não lhe agrava a ninfa" ${ }^{23}$ percebe-se que em algum momento a ninfa agradou o herói. Não se sabe quando esse desagrado começou, mas ele não pode negar a relação entre os dois personagens. Então, aceita-se o pressuposto

\footnotetext{
${ }^{22}$ Curiosamente, não apenas Odisseu teve filhos com Calipso, mas também teve filhos com Circe. Para ver mais, Cf. HESÍODO (2013).

${ }^{23}$ Para estudo mais aprofundado sobre essa questão específica, cf. ASSUNÇÃO, 2011.
} 
de que essa relação existiu, mesmo que não legítima ou consagrada com o ritual da nymphagôgia.

Com a partida iminente do herói, Calipso tenta de diversas maneiras convencê-lo para que permaneça com ela por mais tempo. Assim, Calipso utiliza suas três ferramentas de sedução: 1. O ocultamento; 2. A beleza; 3. A oferta da imortalidade e juventude eterna. Porém, usando dos aspectos inerentes a sua ilha como auxílio nessa tarefa, acaba por encontrar novos dilemas. Mas por que mesmo munida de tantos artifícios de sedução, Calipso não consegue encantar Odisseu por mais tempo?

Mesmo com todos os anos que permanece com a ninfa e mesmo oculto, é permitido a Odisseu seguir viagem e utilizar esse feito na construção de sua fama entre os humanos. Ele parece aproveitar a oportunidade e assim o faz ao se apresentar para a rainha Arete:

Uma ilha, Ogígia, longe do mar encontra-se.

Lá a filha de Atlas, a ardilosa Calipso, mora, a

bela-tranças, fera deusa; ninguém a ela se une,

nenhum deus, nenhum homem mortal.

Mas a mim, desgraçado, divindade guiou a seu lar...

(Od. 7 . 244-248)

Deste modo, a primeira característica de sedução de Calipso aparece com uma dupla atividade. Oculta aqueles que permanecem consigo, mantendo-os fora da vida cotidiana, em um território estagnado. Os que conseguem partir de sua ilha utilizam essa realização como símbolo de um grande feito entre deuses e humanos. É importante salientar que Calipso, assim como as ninfas humanas, tem por objetivo efetivar o ritual da nymphagôgia ${ }^{24}$. E, para tanto, suas características de sedução existem para concretizar esse ato.

Além dos aspectos já citados, Calipso possui como poder de sedução, nada menos que o oferecimento da imortalidade e juventude eterna, que, ao perceber que os outros não seriam suficientes para Odisseu permanecer, a ninfa oferece como uma possibilidade.

\footnotetext{
${ }^{24}$ É importante salientar que, na Grécia antiga, para a mulher mais ainda do que para os homens, os desdobramentos das dádivas de Afrodite são consagrados pelo casamento, essa instituição da qual se afirmou muito frequentemente que excluía, na Grécia clássica, a satisfação do desejo e da sexualidade em geral. Para ver mais, cf. CALAME, 2013.
} 
Assim, a ninfa diz: "a ele eu acolhia, alimentava e dizia que o faria imortal e sem velhice por todos os dias" (Od. 5.135-136). A ninfa insiste mais uma vez na oferta de imortalidade:

Se soubesse, em seu juízo, quantas agruras

deverás aguentar antes de atingir a terra pátria,

ficando aqui mesmo, comigo cuidarias desta casa e imortal seriais, embora ansiando ver tua esposa, que sempre desejas todos os dias. (Od. 5.206-210).

Todavia, para Odisseu, ao aceitar essa oferta, haveria um preço a pagar. Ele tem vontade de ter sua história para sempre lembrada, mas sabe que escolher viver uma vida como imortal junto à ninfa o levaria ao esquecimento.

É sabido que o kléos áphtiton, a "fama imperecível”, não advém da criação dos humanos ${ }^{25}$, mas através de um conjunto de elementos eternos, algo parecido com os elementos eternos da palavra, possuidora de uma existência objetiva na vida das sociedades e suas tradições. Nesse caso, a imortalidade que Odisseu busca vem através do canto do aedo, aquele que narra sua história para as gerações futuras (SEGAL, 2001, p. 86). A vontade de Odisseu de conseguir esse feito é tamanha, que após recusar o presente de juventude e imortalidade vinda de Calipso, o próprio herói canta seus feitos para Alcino: "Sou Odisseu, filho de Laerte, que, por ardis, por todos os homens sou conhecido: minha fama o páramo atinge" (Od, 9.019-20).

Calipso retém a beleza das deusas e, em conjunto com sua morada, seduz as poucas pessoas que passam pela longínqua ilha. Mesmo possuindo beleza divina, ela se equipara à mortal Penélope ${ }^{26}$ :

Com certeza não pior que ela proclamo ser, nem no porte, nem no físico, pois não é possível que as mortais disputem com imortais em porte e aparência (Od. 5. 211-213).

\footnotetext{
${ }^{25}$ Cabe salientar que a criação da fama não ocorre apenas pelos homens, mas também pelas mulheres. Na própria Odisseia é possível ver a criação do Kléos de Penélope através da história da mortalha que tecia durante o dia e desfazia de noite, enganando os pretendentes (Od. 2, 90 - 105).

${ }^{26}$ É interessante notar que na Odisseia, mesmo compartilhando do estatuto das mulheres, Penélope é considerada uma nymphê (Od. 4 743-744) mesmo sendo casada e com filhos. Curiosamente, Penélope, mesmo já tendo efetivado o ritual da nymphagogia, é obrigada a realizá-lo novamente caso Odisseu não retorne, permanecendo em um estado de transição ao qual não se encaixa no estatuto. Cabe então indagar em qual estatuto se encaixa a mulher viúva com filhos?
} 
Por que Calipso se equipara à beleza da mortal Penélope? A ninfa possui beleza que causa admiração e assombro, então, por que mesmo consciente de sua superioridade, ela ainda coloca Odisseu a prova? A união dos elementos presentes em Calipso e sua ilha parecem corresponder a tudo que é mais belo e importante para os humanos. A tarefa de Odisseu, entretanto, é fugir.

Esse triângulo ${ }^{27}$ entre os personagens na Odisseia ganha força através do esquecimento de Odisseu durante o tempo que passa com Calipso, pois ele oscila entre a ninfa imortal e a ninfa mortal. A escolha entre uma das duas implica para o herói uma vida imortal em esquecimento ou uma vida mortal em glórias. Odisseu, ao rejeitar Calipso, o casamento, e a oferta da imortalidade e juventude eterna para continuar com seu casamento com Penélope, mantêm seu estado social e a garantia de sua glória como herói. Isso ocorre uma vez que, voltando para sua esposa legítima, permanece no cotidiano (PACHE, 2013, p.6).

Esses três aspectos que emanam da ninfa Calipso articulam-se e atuam como ferramentas para a realização de sua vontade. Através de sua beleza eterna, de sua capacidade de ocultamento e da oferta de imortalidade e juventude eterna, resistir à ninfa parece impossível sem a interferência dos deuses.

É mister recordar que, no final da história de Odisseu e Calipso, a ninfa promete ajudar o herói e diz que nada mais irá ocultar para que ileso retorne à sua pátria e à sua esposa (Od. 5.144). A ninfa possibilita que o rei de Ítaca construa uma jangada através de um grande machado ( $\mathrm{Od} .236)$ e lhe faz provisões, mesmo que em um tom diferente de Circe, sobre o que lhe aguarda em Ítaca (SAÏD, 2010, p. 36).

Com essa atitude, a ninfa demonstra que a característica de ocultamento é inerente a sua existência, sendo a única forma do viajante evitar o esquecimento é indo embora de Ogígia. Desse modo, Calipso possibilita que Odisseu retorne a sua pátria. Perde ela, no entanto, a oportunidade de consagrar o ritual da nymphagôgia. Com isso, a ninfa abandona a possibilidade de não permanecer sozinha em sua ilha, entre o mundo dos deuses e dos homens, já que deixar esse destino não é uma opção.

\footnotetext{
${ }^{27}$ Pode-se questionar se o triângulo amoroso estabelecido entre Calipso, Odisseu e Penélope possibilita realizar leituras sobre o estatuto das mulheres e como essa relação poderia se estabelecer dentro do oikos. Penélope é esposa legítima de Odisseu, mas e quanto a Calipso? Seria possível compará-la a postura de uma concubina?
} 


\section{Considerações finais}

Ao considerar a figura de Calipso, averigua-se que a nymphê pode ser interpretada através do estatuto das mulheres, além de conter em si outras características reservadas às divindades imortais. Analisando o estatuto das mulheres, a definição contida do que é ser uma nymphê, distancia-se de Circe, pois em momento algum ela demonstra buscar o casamento. Já no caso de Calipso, é indiscutível sua vontade de efetivar o casamento com aqueles que passam pela sua ilha. Além disso, é preciso lembrar que Calipso possui práticas de outras deusas, como se alimentar de néctar e ambrosia (BOUFFARTIGUE, 2006, p. 58).

Com esse artigo é possível questionar os propósitos da ninfa Calipso de consagrar o ritual da nymphagôgia do mesmo modo que toda nymphê, e conciliar o fato de possuir em si a característica de esconder os que estão consigo. Na Odisseia, em termos gerais, ela é descrita como uma ninfa em busca da efetivação do ritual da nymphagôgia. Porém, Odisseu não permanece com a ninfa, pois, apesar de reconhecer a superioridade de Calipso em relação à mulher mortal, ele insiste em afirmar o seu amor por uma mulher que, como ele, está envelhecendo e vai morrer um dia.

O herói apenas retoma os termos genéricos do retorno à casa e do dia do regresso, assim como sua disposição - dada a sua natureza mortal e heroica - para o sofrimento tanto na guerra quanto no mar (Od. 5. 215-220). Calipso não representa para o herói antigo, uma conquista inalcançada, ou alguém que ele não tivesse controle. Nessa perspectiva, Calipso é independente e, no caso de Odisseu, rompe com seus desígnios, e, por mais que seja guiada pela vontade de efetivar o casamento, ela compreende que precisa deixar o herói partir, já que não é o seu destino permanecer oculto com a ninfa.

Desse modo, no contexto da Odisseia, o herói não se apresenta como uma figura que busca uma supremacia sobre outros povos. Em momento nenhum do canto quinto ele busca ser o "senhor" de Ogígia, ou questiona a autoridade de Calipso. Como já foi visto, o grande feito de Odisseu nessa obra é conseguir chegar à Ítaca vivo, dado que uma das características inatas de Calipso é esconder da história quem estiver consigo e isso para o humano grego é equivalente à morte, pois ninguém contará sua história (BOUVIER, 2002, p.8). 
Sobre a relação entre as ninfas mortais e imortais, Calipso permanece em um estatuto intermediário. Mas, esse estatuto, além de manter a ninfa entre mortais e imortais, não garante que esse seja um espaço transitório da mesma forma que acontece com as ninfas humanas (DALMO, 2015, p. 11). Outrossim, Calipso diferencia-se das demais ninfas presentes no estatuto das mulheres, pois, independente de efetivar o ritual da nymphagôgia, ela continuaria como uma ninfa, vivendo em sua ilha.

Por fim, faz-se necessário indicar as similaridades entre Calipso e as Hetairas, que se relacionam com os homens, mas não necessariamente possuem legitimidade ou são reconhecidas como esposas. Porém, se reconhece que dados os limites desse artigo não foi possível verificar essas semelhanças com profundidade.

A única certeza que se tem sobre a Calipso narrada por Homero é que ela não consegue ultrapassar os limites de sua existência. Criada como uma nymphê que oculta, dificilmente conseguiria alcançar seus objetivos em um período marcado pela busca dos humanos pela glória eterna. Fadada a viver isolada, a ninfa permanece eternamente sozinha em sua ilha.

\section{Referências Bibliográficas Primárias:}

HOMERO. (2014). Odisseia. Apresentação de Martin Richard, Tradução e introdução de Christian Werner. São Paulo: Cosac Naify.

HOMERO. (2011). Odisseia. Tradução e prefácio de Frederico Lourenço e introdução e notas de Bernard Knox. São Paulo: Companhia das letras.

\section{Secundárias:}

ASSUNÇÃO, T.R. (2011). Infidelidades veladas: Ulisses entre Circe e Calipso na Odisseia in Nuntius antiquus. Belo Horizonte,v.VII, n.2. pp. 153-176.

BOUVIER. P. (2002). Le Pouvoir de Calypso: a propos d'une poétique Odysséenne., In: A. Hurst et F. Létoublon (éd.), La mythologie et l'Odyssée. Hommage à Gabriel Germain, Genève, pp. 69-85. 
BOUFFARTIGUE J.(2006). Calypso, entre nom et personnage. In: $\Phi$ ı $\lambda \mathrm{o} \lambda \mathrm{o}$ í́ $\alpha$. Mélanges offerts à Michel Casevitz. Lyon : Maison de l'Orient et de la Méditerranée Jean Pouilloux. pp. 57-65.

BUTLER, S. (1897). The authoress of the Odyssey. USA: Library of Alexandria.

BUFFIERE, F. (1956). Les mythes d'Homère et la pensée Grecque.

CALAME, C. (2013). Eros na Grécia Antiga. São Paulo: Perspectiva.

DALMON, S. (2011). Entre l'humain et le divin : le statut intermédiaire des Nymphes dans la poésie épique grecque archaïque. Paris: Université Paris-Diderot, pp. 38-49.

DALMON, S. (2015). Les Nymphes entre maternité et courotrophie dans les Hymnes homériques. Cahiers « Mondes anciens » 6. pp. 2-15.

GANTZ, T. (2004). Mythes de la Grèce Archaïque. Paris: Berlin.

LISSARRAGUE, F. (1990). Femmes au figure. In: DUBBY, G.; PERROT, M. (orgs) Histoire des femmes en Occident: I. L’Antiquité. Roma: Tempus, Perrin, p. 203-305.

LOUDEN, B. (1999). The “Odyssey”. Structure, narration, and meaning. Baltimore: The Johns Hopkins University Press.

LORAUX, N. (1990). Qu'est-ce qu'une Déesse? In DUBBY, G.; PERROT, M. (orgs) Histoire des femmes en Occident: I. L’Antiquité. Roma: Tempus, Perrin, p. 39-79.

MAGNIEN, V. (1936). Le mariage chez les Grecs anciens: l'initiation nuptiale, Antiquité Classique, Bruzelles.

PACHE, C. O. (2013). A Moment's Ornament: The Poetics of Nympholepsy in Ancient Greece. Oxford Scholar ship.

RIBEIRO JUNIOR, W. A. (2010). (org). Hinos Homéricos. São Paulo: Editora UNESP. SAÏD, S. (2010). Homère et l’Odyssée. Paris: Berlin.

SEGAL, C. (2001). Singers, Heroes, and Gods in The Odyssey. New York: Cornell University. VERNANT, J.P. (1989). L'individu, la mort, l'amour. Paris: Folio historie.

WERNER, C. (2001). A Ambiguidade do Kléos na Odisséia. Letras Clássicas, n.5. p. 99-108. 